\title{
INVESTIGATION OF PROCESSES LEADING TO THE DECLINE OF SOUTH AUSTRALIA'S CALADENIA SPECIES
}

\author{
Renate FAast ${ }^{1} \&$ José M. Facelli \\ School of Earth and Environmental Sciences, University of Adelaide, Australia 5005 \\ ${ }^{1}$ Author for correspondence: renate.faast@adelaide.edu.au
}

Of the 300 species of orchids recorded in South Australia, over one-third have been listed as vulnerable, rare, or endangered (Barker et al. 2005). While direct habitat loss is likely to be the major cause for reductions in the former ranges of species, indirect consequences of habitat fragmentation may be responsible for the continued decline of many species within remnant fragments. Reduction of genetic diversity (Ellstrand \& Elam 1993, Young et al. 1996,), disruption of plant-pollinator interactions (Aizen \& Feinsinger 1994, Lennartsson 2002) and changes in habitat characteristics (Tremblay 2005) can all influence the population dynamics and hence, persistence of, a species across a landscape.
We are investigating the potential causes of the continued decline of several orchid species within the genus Caladenia occurring within the highly fragmented landscape of the Mt. Lofty ranges. We have made assessments of pollination and reproductive success across a range of habitat fragments and will relate these to the influences of population size, fragment size, isolation, disturbance and local habitat structure. Furthermore, studies over consecutive years will allow us to assess the costs of reproduction and herbivory on future plant fitness. This research provides an insight into processes leading to the decline of some orchid species and hence has important implications for management and conservation strategies.

\section{LITERATURE CITED}

Aizen, M.A. \& P. Feinsinger. 1994. Forest fragmentation, pollination, and plant reproduction in a Chaco dry forest, Argentina. Ecology 75: 330-351.

Barker, W.R., R.M. Barker, J.P. Jessop, J.P. \& H.P. Vonow. 2005. Census of South Australian Vascular Plants. $5^{\text {th }}$ Edition. J. Adelaide Botanic Gardens Supplement 1. Botanic Gardens of Adelaide and State Herbarium: Adelaide.

Ellstrand, N.C. \& D.R. Elam. 1993. Population Genetic Consequences of Small Population-Size - Implications for Plant Conservation. Ann. Rev. Ecol. Syst. 24 :217-242.

Lennartsson, T. 2002. Extinction thresholds and disrupted plant-pollinator interactions in fragmented plant populations. Ecology 83: 3060-3072.

Tremblay, R.L., J.D. Ackerman, J.K. Zimmerman, J.K. \& R.N. Calvo. 2005. Variation in sexual reproduction in orchids and its evolutionary consequences: a spasmodic journey to diversification. Biol. J. Linn. Soc. 84: 1-54.

Young, A., T. Boyle \& T. Brown. 1996. The population genetic consequences of habitat fragmentation for plants. Tree 11: $413-418$. 